\title{
Among-tree variation in leaf phenology and morphology and its correlation with insect performance in the mountain birch
}

\author{
Josef Senn, Sinikka Hanhimäki and Erkki Haukioja
} Senn, J., Hanhimäki, S. and Haukioja, E. 1992. Among-tree variation in leaf
phenology and morphology and its correlation with insect performance in the moun-
tain birch. - Oikos 63: 215-222.

\begin{abstract}
We studied variation in leaf morphology and phenology in a population of the mountain birch (Betula pubescens ssp. tortuosa) in northernmost Finland over two summers. We tested tree quality with bioassays using several leaf-eating insect species to study the impact of plant variation on herbivore performance.

Leaf size and phenology varied considerably between years. Differences among trees were significant, but individual trees retained their leaf-character-ranking within and between seasons. Positive correlations between tree height and leaf size and differences in bud growth patterns indicate that the mountain is genetically related to the dwarf birch, B. nana. On tall, large-leaved trees, which flushed early in spring, herbivores grew fast, whereas lower nana-like trees with smaller leaves leafing out late represented poor quality food. This pattern varied between years, being stronger in a summer when the trees produced relatively small poor quality leaves than in a summer when the trees produced larger leaves on which the herbivores grew faster. However, the mean growth rates of herbivores on individual trees were significantly correlated between the years. In general, tree quality seems to depend on the temperature conditions of the previous summer, although a current year's high temperatures may mould leaf quality by altering the maturation pattern of the leaves. Polymorphism within a mountain birch population may be partially maintained by conflicting selection pressures: periods with advantageous climatic conditions and low herbivore pressure should favour taller, large-leaved trees, whereas the episodes of high herbivore pressure should favour low, small-leaved trees.
\end{abstract}

Josef Senn, Zoological Inst. of the Univ., Rheinsprung 9, CH-4051 Basel, Switzerland (present address: Swiss Federal Inst. for Forest, Snow and Landscape Research, CH-8903 Birmensdorf, Switzerland). - Sinikka Hanhimäki and Erkki Haukioja, Laboratory of Ecological Zoology, Dept of Biology., Univ. of Turku, SF-20500 Turku, Finland and Kevo Subarctic Research Station

A plant population is not a mass of uniform individuals. For instance, some plant individuals may be heavily infested with insect herbivores year after year, whereas nearby individuals of the same plant species may be almost free of insects (e.g., Whitham 1983, Leather 1986, Crawley and Akhteruzzaman 1988 and references therein). Such observations point to some interesting questions: (a) how much variation is there among plants in physical, chemical and developmental traits, and (b) how does this variation explain herbivore performance?

In this study we examined individual mountain birch trees (Betula pubescens ssp. tortuosa (Ledeb.) Nyman) growing in a natural stand over two seasons to find out the relationship between leaf phenology, morphology and other tree characters, and insect performance. The mountain birch is interesting for this kind of study because it shows extensive variation both in tree architecture and in leaf morphology (Vaarama and Valanne 1973). This is thought to be caused in part by introgressive hybridisation between the tree-like Betula pubescens (Ehrh.) and the small-leaved, low, polycormic bush Betula nana L. (Elkington 1968, Sulkinoja 1981, Kallio et al. 1983, Sulkinoja and Valanne 1987). To assess the quality of the trees for herbivores, we mea- 
Table 1. Herbivore species used in the growth trials to determine tree quality.

$\begin{array}{cl}\begin{array}{c}\text { Lepidoptera } \\ \text { Geometridae } \\ \text { Hymenoptera }\end{array} & \text { Epirrita autumnata (Borkhausen) } \\ \text { Argidae } & \text { Arge fuscinervis Lindqvist } \\ \text { Tenthredinidae } & \begin{array}{l}\text { Amauronematus fallax (Lepeletier) } \\ \text { Amauronematus lindqvisti Hellén } \\ \text { Nematus brevivalvis Thomson } \\ \text { Nematus pravus (Konow) } \\ \text { Nematus viridis Stephens } \\ \text { Priophorus pallipes (Lepeletier) }\end{array} \\ & \end{array}$

sured the growth of larvae of eight insect species on leaves from these mountain birches. Furthermore, we correlated the recorded plant characters with the growth performance of the insect herbivores to describe the relationship between easily measurable plant characters and herbivore performance.

\section{Material and methods}

\section{Study site and plants}

The study was conducted near the Kevo Subarctic Research Station in northern Finland $\left(69^{\circ} 45^{\prime} \mathrm{N}, 27^{\circ} 01^{\prime} \mathrm{E}\right)$.

Twenty mature birch trees were randomly chosen in a homogeneous forest plot and marked individually. We recorded date of the leaf flush and leaf samples were taken in 1987 and 1988. In both years we sampled 30 short shoot leaves from each tree in early summer, after leaf growth had terminated. To facilitate comparisons between years, the collection dates in 1988 were determined to match the accumulated thermal sums (above the base of $+5^{\circ} \mathrm{C}$; dd5 in Table 2) in 1987. Another sample of 30 leaves was collected before leaf senescence in late summer. We weighed the leaves fresh and after drying at $60^{\circ} \mathrm{C}$ for $48 \mathrm{~h}$ to $\pm 0.1 \mathrm{mg}$. Leaf area was obtained from photocopied leaves by an area digitiser (Numonics Digitablet, Model 2400). From these measurements we calculated water content and specific leaf weight, both on fresh and dry weight basis, and used the tree-specific means to characterise the trees.

In 1988 we measured bud length from 10 buds on each of five branches ( 50 buds from each tree) on June 1,7 , and 15 to estimate the physiological advancement of growth in individual trees. We scored bud development in four classes: 1 = 'closed brown buds', $2=$ 'little green visible', $3=$ 'expanding leaves', and $4=$ 'expanded short shoots'.

An additional leaf sample, to study the relationship between leaf development in spring and senescence in autumn, was taken on 9 September 1988, when leaves in the first trees started to change colour. To assess the pattern of colour change, we visited the trees on 8,12 and 16 September and scored each tree in one of the following five classes: 1 = 'all leaves green', $2=$ 'green leaves with minor changes to yellow', $3=$ 'equal amount of green and yellow leaves', $4=$ 'all leaves non-green', and $5=$ 'a considerable number of the leaves lost'.

We measured tree height in early summer 1989 .

\section{Herbivore growth}

Larval growth rate was used as an index of tree quality. This was done by measuring the relative growth rates of larvae in $24 \mathrm{~h}$ in a climate room at constant temperature $\left(12^{\circ} \mathrm{C} \pm 1^{\circ}\right)$. These tests were conducted with late instar larvae of one lepidopteran and seven sawfly species (Table 1) at similar degree days in both years. Three to five individuals of each insect species were used per tree. All herbivore species were originally collected

Table 2. Means $\pm 1 \mathrm{SE}$ of the measured leaf parameters in each sample of 1987 and 1988 . Means with the same letter are not significantly different (at $\mathrm{P}=0.05$; Student-Newman-Keuls-test). Cumulative temperature sum (base of $5^{\circ} \mathrm{C}$ ) is given as dd5. Specific leaf weight was calculated as weight/area and using fresh and dry leaf weights. Number of trees $=20$.

\begin{tabular}{|c|c|c|c|c|c|}
\hline \multirow{2}{*}{$\begin{array}{l}\text { Year } \\
\text { Leaf sample }\end{array}$} & \multicolumn{2}{|c|}{1987} & \multicolumn{3}{|c|}{1988} \\
\hline & 1 & 2 & 1 & 2 & 3 \\
\hline $\begin{array}{l}\text { Date } \\
\text { dd5 }\end{array}$ & $\begin{array}{c}\text { July } 16 \\
188\end{array}$ & $\underset{390}{\text { August }} 20$ & $\begin{array}{c}\text { June } 29 \\
188\end{array}$ & $\begin{array}{c}\text { July } 24 \\
430\end{array}$ & $\begin{array}{c}\text { September } 9 \\
732\end{array}$ \\
\hline $\begin{array}{l}\text { Leaf parameters\$: } \\
\text { Fresh weight [mg] } \\
\text { Dry weight }[\mathrm{mg}] \\
\text { Water content }[\%] \\
\text { Leaf area }\left[\mathrm{cm}^{2}\right] \\
\text { Spec. leaf weight (fresh) } \\
\text { Spec. leaf weight (dry) }\end{array}$ & $\begin{array}{r}162.7 \pm 7.1 \mathrm{a} \\
58.0 \pm 2.6 \mathrm{a} \\
64.3 \pm 0.4 \mathrm{a} \\
8.0 \pm 0.4 \mathrm{a} \\
20.5 \pm 0.3 \mathrm{a} \\
7.3 \pm 0.2 \mathrm{a}\end{array}$ & $\begin{array}{c}162.1 \pm 7.2 \mathrm{a} \\
62.4 \pm 2.7 \mathrm{a} \\
61.5 \pm 0.3 \mathrm{~b} \\
7.3 \pm 0.4 \mathrm{ab} \\
22.3 \pm 0.4 \mathrm{~b} \\
8.6 \pm 0.2 \mathrm{~b}\end{array}$ & $\begin{array}{r}135.0 \pm 6.1 \mathrm{a} \\
43.9 \pm 2.0 \mathrm{~b} \\
67.4 \pm 0.4 \mathrm{c} \\
6.5 \pm 0.3 \mathrm{~b} \\
20.8 \pm 0.3 \mathrm{a} \\
6.8 \pm 0.2 \mathrm{c}\end{array}$ & $\begin{array}{c}151.8 \pm 7.1 \mathrm{a} \\
54.5 \pm 2.5 \mathrm{a} \\
64.0 \pm 0.4 \mathrm{a} \\
7.1 \pm 0.4 \mathrm{ab} \\
21.5 \pm 0.3 \mathrm{ab} \\
7.7 \pm 0.2 \mathrm{a}\end{array}$ & $\begin{array}{r}160.8 \pm 7.9 \mathrm{a} \\
59.9 \pm 3.0 \mathrm{a} \\
62.8 \pm 0.4 \mathrm{~d} \\
- \\
- \\
-\end{array}$ \\
\hline
\end{tabular}

${ }^{8}$ ANOVA results for differences between samples using tree means as observations: Fresh weight $F=2.74, P=0.0332 ; D r y$ weight $F=7.77, P<0.0001$; Water content $F=37.25, P<0.0001$; Leaf area $F=2.91, P=0.0401$; Specific leaf weight (fresh) $F=4.81$, $\mathrm{P}=0.0040$; Specific leaf weight (dry) $\mathrm{F}=20.40, \mathrm{P}<0.0001$. 
Table 3. Results of the one-way ANOVAs (F-value, *** $\mathrm{P}<0.001)$ of leaf parameters and the distribution of variance (\%) into among tree and error (including within tree variance) component in different leaf samples. Measurements taken from 20 trees and 30 leaves from each; data balanced.

\begin{tabular}{|c|c|c|c|c|}
\hline & \multicolumn{2}{|c|}{ ANOVA-results } & \multicolumn{2}{|c|}{ Variance distribution } \\
\hline & $\mathrm{F}$ & & Among tree & Error \\
\hline \multicolumn{5}{|c|}{ Fresh weight } \\
\hline $1 / 87$ & 30.38 & $* * *$ & 49.5 & 50.5 \\
\hline $2 / 87$ & 25.59 & $* * *$ & 45.0 & 55.0 \\
\hline $1 / 88$ & 21.61 & $* * *$ & 40.7 & 59.3 \\
\hline $2 / 88$ & 24.49 & $* * *$ & 43.9 & 56.1 \\
\hline $3 / 88$ & 45.10 & $* * *$ & 59.5 & 40,5 \\
\hline \multicolumn{5}{|c|}{ Dry weight } \\
\hline $1 / 87$ & 32.23 & $* * *$ & 51.0 & 49.0 \\
\hline $2 / 87$ & 23.82 & $* * *$ & 43.2 & 56.8 \\
\hline $1 / 88$ & 21.11 & $* * *$ & 40.1 & 59.9 \\
\hline $2 / 88$ & 24.90 & $* * *$ & 44.3 & 55.7 \\
\hline $3 / 88$ & 44.66 & $* * *$ & 59.3 & 40.7 \\
\hline \multicolumn{5}{|c|}{ Water content } \\
\hline $1 / 87$ & 138.40 & $* * *$ & 82.1 & 17.9 \\
\hline $2 / 87$ & 76.26 & $* * *$ & 71.5 & 28.5 \\
\hline $1 / 88$ & 96.49 & $* * *$ & 76.1 & 23.9 \\
\hline $2 / 88$ & 82.97 & $* * *$ & 73.2 & 26.8 \\
\hline $3 / 88$ & 88.57 & $* * *$ & 74.5 & 25.5 \\
\hline \multicolumn{5}{|c|}{ Leaf area } \\
\hline $1 / 87$ & 37.79 & $* * *$ & 55.1 & 44.9 \\
\hline $2 / 87$ & 36.49 & $* * *$ & 54.2 & 45.8 \\
\hline $1 / 88$ & 30.27 & $* * *$ & 49.4 & 50.6 \\
\hline $2 / 88$ & 32.50 & $* * *$ & 51.2 & 48.8 \\
\hline \multicolumn{5}{|c|}{ Specific leaf weight (fresh) } \\
\hline $1 / 87$ & 61.06 & $* * *$ & 66.7 & 33.3 \\
\hline $2 / 87$ & 68.56 & $* * *$ & 69.2 & 30.8 \\
\hline $1 / 88$ & 41.77 & $* * *$ & 57.6 & 42.4 \\
\hline $2 / 88$ & 41.69 & $* * *$ & 57.6 & 42.4 \\
\hline \multicolumn{5}{|c|}{ Specific leaf weight (dry) } \\
\hline $1 / 87$ & 76.08 & $* * *$ & 71.4 & 28.6 \\
\hline $2 / 87$ & 58.96 & $* * *$ & 65.9 & 34.1 \\
\hline $1 / 88$ & 47.60 & $* * *$ & 60.8 & 39.2 \\
\hline $2 / 88$ & 46.09 & $* * *$ & 60.2 & 39.8 \\
\hline
\end{tabular}

from mountain birches, and in the growth trials we used their first and second generation progenies. We tested the larvae at times of their natural occurrence.

\section{Results}

\section{Variation in leaf parameters}

Temporal variation. All recorded leaf parameters showed significant differences among sampling dates (Table 2). The smallest leaves were collected on 29 June 1988 , according to fresh and dry mass and leaf area, although the phenological state was controlled for by collecting leaf samples on the same degree-day each year. On that same date leaf water content was highest $(67.4 \%)$. Specific leaf weight (both fresh and dry) was lowest in the early season samples. In both seasons the specific leaf weight increased significantly through the summer, which is the usual case (see Ayres and MacLean 1987), but the increment was smaller in 1988 than in 1987. The mean leaf dry weight was significantly lower in the early summer of 1988 than of 1987 (Table 2). The same was true for leaf area. Leaf development was retarded in 1988 as indicated by a slower decrease in leaf water content in 1988 than in 1987, and correspondingly less photosynthates were accumulated per leaf area (specific weight of dry leaves was lower in 1988 than in 1987). However, in late summer 1988 the leaves were as heavy as in 1987; they could thus compensate for the slow start. In contrast, water content was significantly lower in 1987 than in 1988, and consequently, specific leaf weight (dry) was significantly higher in the first summer.

Variation among trees. The trees differed significantly on each sampling date (Table 3). The distribution of variance into among and within tree components (expressed with error variance) was analysed with a nested ANOVA (SAS 1985) for each leaf sample (Table 3). Tree differences accounted for $40.1-59.5 \%$ of the variance in leaf weight and area, for $60.0-71.5 \%$ in specific leaf weight, and $71.5-82.1 \%$ for the variation in leaf water content. Mean leaf size and mass varied by a factor of two among trees, and, on a given date, differences in water content among trees equalled the average differences between samples of early and late summer. For all leaf parameters tree-specific values were positively correlated within and between seasons (Pearson correlation coefficient is 0.76 to 0.98 and $\mathrm{P}<<0.001$ ), except for water content in the autumn sample of 1988.

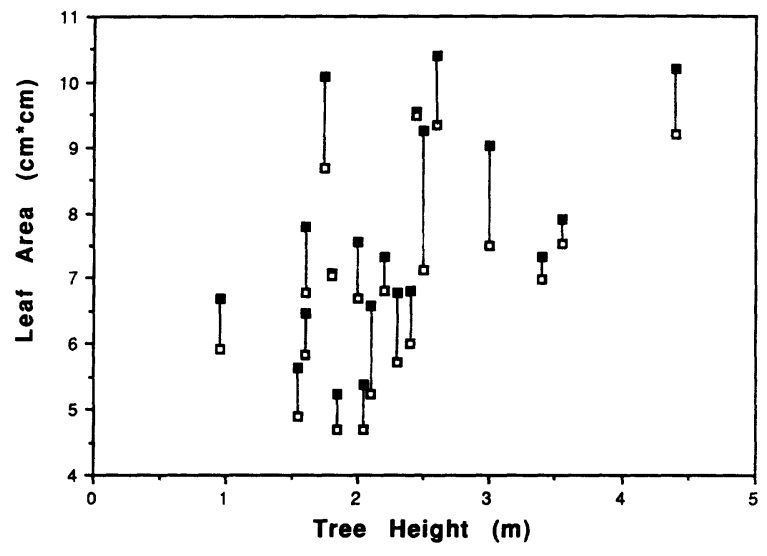

Fig. 1. The average leaf area (means of the first and the second leaf sample) as a function of tree height. Solid squares for 1987, open squares for 1988. Lines connect the two years for each tree. Regression lines: in $1987 \mathrm{y}=0.99 \mathrm{x}+5.37, \mathrm{r}=0.49, \mathrm{P}=0.03$; in $1988 \mathrm{y}=0.96 \mathrm{x}+4.59, \mathrm{r}=0.51, \mathrm{P}=0.02, \mathrm{n}=20$. 


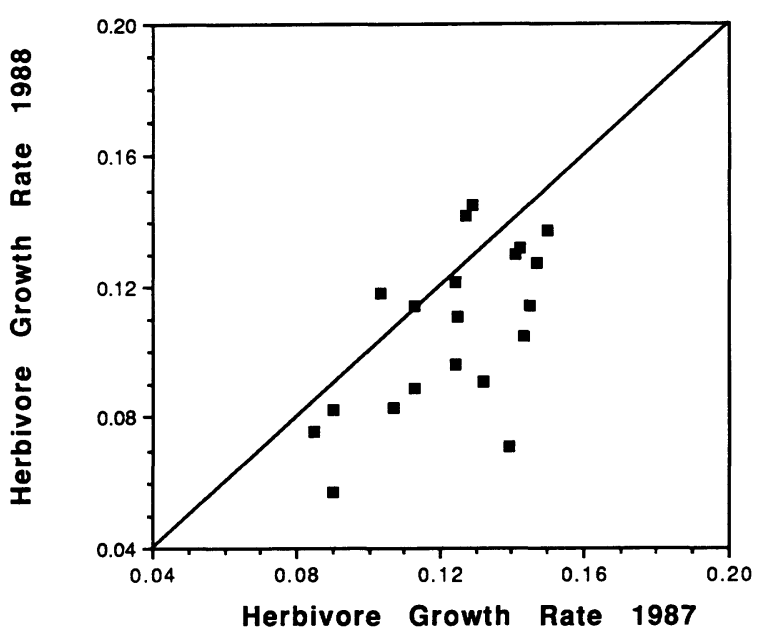

Fig. 2. The average growth rate of all herbivore species (calculated as tree-specific means) in 1987 compared to growth rates in 1988 on the same trees. The line indicates identical growth rates on the same trees in the two years. Regression line: $\mathrm{y}=0.76 \mathrm{x}+0.01, \mathrm{r}=0.60, \mathrm{P}=0.005, \mathrm{n}=20$. Mean growth rates were significantly different between the two years (paired $t$ test: $\mathrm{t}=3.53, \mathrm{P}=0.002$ ).

\section{Correlations between leaf and other tree parameters}

Leaf area (Fig. 1) as well as leaf fresh and dry weight were positively correlated with tree height $(\mathrm{P}<0.05)$. Thus, the tallest trees had the largest leaves. Leaf water content and specific leaf weight did not correlate significantly with tree height, and most of those correlations were negative.

Bud development. On 1 June 1988 (the first date for bud measurement), the buds of ten of our twenty trees were still closed. In nine other trees the buds were swollen, and only one tree had the buds almost open. Bud length correlated positively with tree height $(\mathrm{r}=0.46, \mathrm{P}=0.04)$, indicating that the biggest trees had the largest buds. On 7 June, all trees, except one, had expanding buds at different stages, and on 15 June, fifteen of the trees had open buds and shoots were growing. Between the last two dates, the relative growth rate of the buds was on average twice as rapid $(0.61)$ as between the first and the second date $(0.29)$. The growth rate of the buds provided a good prediction for final leaf weight and area: the trees with the largest buds had the most rapid bud expansion and produced the largest leaves.

In early summer, water content of the leaves correlated significantly negatively with the early growth of the buds (between the 1st and 2nd measurement) $(\mathrm{r}=-0.64, \mathrm{P}=0.002)$. Between early bud growth and specific leaf weight in early summer 1988 there was a marginally significant positive correlation $(r=0.41$, $\mathrm{P}=0.07)$. These two correlations suggest that those trees which leafed out early and grew fast had also mature leaves earlier than the others. Early bud growth in 1988 correlated significantly with leaf water content of the early summer $1987(\mathrm{r}=-0.56, \mathrm{P}=0.01)$, indicating a stable pattern in bud growth between the two years. Early bud growth did not correlate with water content nor with specific leaf weight in any later leaf sampling date. Later bud growth (between the 2nd and the 3rd measurement) did neither correlate with these leaf parameters.

Colour change in autumn. Trees with the smallest leaves (size determined either by area or by weight) changed the colour of their leaves earlier than trees with large leaves. This was shown by the Spearman correlation coefficients between the fresh, dry weight, or leaf area, and the index of leaf colour change which were consistently negative in all leaf samples. These correlations were significant, however, only in the early autumn sample (leaf fresh weight: $r_{s}=-0.46, P=0.04$; leaf dry weight: $r_{s}=-0.56, P=0.01$; leaf area: $r_{s}=-0.49$, $\mathrm{P}=0.03$ ).

Trees which started to grow latest in spring tended to shed their leaves earliest in autumn. This relationship was indicated by the negative correlation between bud development on 15 June (the last observation in spring) and leaf colour score on 16 September (the last observation in autumn). However, it was only marginally significant $\left(r_{s}=-0.43, P=0.06\right)$. Similarly, trees with the fastest bud growth tended to keep their leaves the longest in autumn. The correlation coefficients between bud growth and leaf colour index in autumn were consistently negative but only marginally significant.

\section{Plant characteristics and herbivore growth}

Variation in insect growth between trees and years. In 1987 the mean growth rate of the herbivores on the best tree was 1.8 times higher than that on the worst tree, whereas in 1988 this factor was 2.5. The relative growth rates of insect larvae were significantly lower in 1988 than in 1987 ( $\mathrm{t}$-test: $\mathrm{t}=3.53, \mathrm{P}=0.002$ ) (Fig. 2). This was true although we used larvae in the same physiological stage and age, and conducted all growth trials under standardised laboratory conditions (growth chamber, standard light and temperature regimes) on phenologically eqivalent leaves. In spite of the overall difference between the two years, the mean quality of the individual trees was positively correlated between the two years $(\mathrm{r}=0.60, \mathrm{P}=0.005)$ (Fig. 2).

Insect growth and tree characteristics. In both years herbivore growth correlated positively with leaf area (Fig. 3) and leaf mass (fresh weight 1987: $r=0.32$, $\mathrm{P}=0.16 ; 1988: \mathrm{r}=0.59, \mathrm{P}=0.007)$, and negatively with specific leaf weight (Fig. 4). Although the correlations were non-significant or only marginally significant in 1987, they were highly significant in 1988 (Figs 3, 4). 


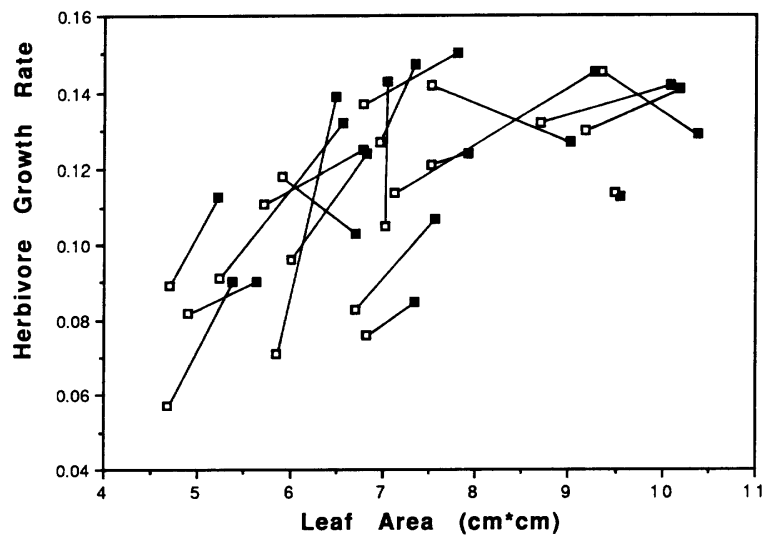

Fig. 3. The relationship between leaf area and average growth rate of the herbivores (means of the first and the second leaf sample) on individual birches. Codes as in Fig. 1. Correlation coefficients: in $1987 \mathrm{r}=0.46, \mathrm{P}=0.04$; in $1988 \mathrm{r}=0.70$, $\mathrm{P}=0.0006, \mathrm{n}=20$. Lines connect the two years for each tree.

Surprisingly, leaf water content did not correlate significantly with herbivore growth (1987: $\mathrm{r}=0.27, \mathrm{P}=0.25$; 1988: $\mathrm{r}=0.31, \mathrm{P}=0.19$ ).

Tree height, which was positively correlated with leaf mass and area (Fig. 1), correlated also positively with herbivore growth (1987: $\mathrm{r}=0.31, \mathrm{P}=0.19 ; 1988$ : $\mathrm{r}=0.40$, $\mathrm{P}=0.08$ ), although this correlation was weak.

\section{Discussion}

\section{Variation in leaf parameters}

Our results clearly demonstrate the high phenotypic diversity of the mountain birch population: all measured leaf parameters differed significantly among trees. This coincides with the results of Karlsson and Nordell (1988) who examined morphological and physiological characters of mountain birch leaves. They found that physiological traits like nitrogen concentration and photosynthetic capacity, which potentially affect herbivore performance, varied to a similar degree among individual trees as did the morphological traits. Differences in leaf nitrogen concentrations among mountain birch individuals are known to be consistent between years (Haukioja et al. 1985, Karlsson and Nordell 1988). This corresponds well with the results of our correlation analyses on tree-specific leaf values, which illustrate that the relative position of individual trees remained constant within and between years, suggesting microsite and/or genetic basis. Microsite as causing the variation in nitrogen concentration of mountain birches is ruled out by the results of Karlsson and Nordell (1988) who found no correlation between nitrogen content of mountain birch leaves and that of other plant species surrounding the sampled birches in different stands.
The variation in leaf morphology between the years may be explained by climatic differences. According to Hustich (1983) temperature is the main factor influencing tree growth at high latitudes, being much more important than precipitation. In 1986, the summer at Kevo was rather warm (617 dd5), whereas the year 1987 was one of the five coldest of the 28 years recorded at the Kevo Meteorological Station (469 dd5), and the year 1988 was one of the five warmest ( 760 dd5). Earlier measurements have shown that leaf size is affected by temperature conditions of the previous year since leaf growth depends primarily upon stored photosynthates and leaf primordia formed in the previous year (Haukioja et al. 1985). Our results indicate that the cold summer 1987 may have led to smaller leaves (Fig. 1), retarded leaf development in the following year (Table 2 ), and to lower specific weight of dry leaves, which means that less photosynthates were accumulated per leaf area. However, our results also suggest that the high temperatures of the current year are important: the trees could exploit the advantageous climate of the year 1988 to compensate for poor initial conditions. They could, to some extent, compensate for the low leaf mass of the early season since in late summer 1988 the leaves were almost as heavy as in 1987 (Table 2).

\section{Correlations between leaf and other tree parameters}

Low trees had relatively small and higher trees large leaves. Our study did not include any juvenile trees (trees were flowering in a good flower year 1989). We could not test directly for a possible interaction between tree age and leaf size because we could not determine the age of our study trees undestructively. Therefore, we measured leaf size and tree height of birches of

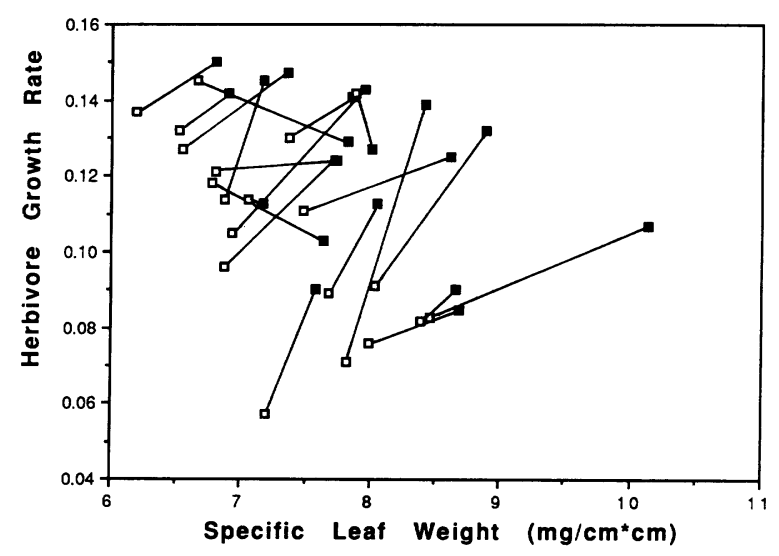

Fig. 4. The relationship between specific leaf weight (dry) and average growth rate of the herbivores (means of the first and the second leaf sample) on individual birches. Codes as in Fig. 1. Correlation coefficients: in $1987 \mathrm{r}=-0.43, \mathrm{P}=0.06$; in $1988 \mathrm{r}=-0.60, \mathrm{P}=0.005, \mathrm{n}=20$. Lines connect the two years for each tree. 
Table 4. Leaf area $\pm 1 \mathrm{SE}$, tree height $\pm 1 \mathrm{SE}$, and number of trees $(\mathrm{N})$ of different birch taxa growing in a common garden at Kevo. Mean age of the trees was equal among taxa ranging from 10 to 14 years.

\begin{tabular}{lccc}
\hline Taxon & $\begin{array}{c}\text { Leaf area } \\
{\left[\mathrm{cm}^{2}\right]}\end{array}$ & $\begin{array}{c}\text { Tree height } \\
{[\mathrm{m}]}\end{array}$ & $\mathrm{N}$ \\
\hline B. pubescens & $8.3 \pm 0.3$ & $1.91 \pm 0.06$ & 62 \\
B. nana $\times$ B. pubescens & $3.9 \pm 0.2$ & $1.46 \pm 0.05$ & 34 \\
B. nana & $1.2 \pm 0.1$ & $0.90 \pm 0.05$ & 27 \\
\hline
\end{tabular}

known age and growing in a common garden near our study site. Those trees were grown from seeds that were collected in the vicinity of the study area and contained mature mountain and dwarf birches and hybrids between the two species (M. Sulkinoja, unpubl.). Mean leaf size and tree height were largest in $B$. pubescens and smallest in $B$. nana (Table 4). Hybrid birches had intermediate values for these traits. Although tree age naturally correlated with tree height, it did not correlate with leaf area within the pubescens- and the hybrid groups. Leaf area and tree height, on the other hand, correlated positively within the pubescens- $(\mathrm{r}=0.40$, $\mathrm{P}=0.001)$ and the nana-groups $(\mathrm{r}=0.79, \mathrm{P}=0.0001)$, as they did in our study trees, but not within the hybrid group.

Since the garden birches were growing under similar soil conditions, we may further exclude site-specific variation in nutritional conditions as a cause for the positive correlation between tree height and leaf size (see Haukioja et al. 1985, Karlsson and Nordell 1987). Therefore, height growth and leaf size in the mountain birch must have a genetical component and may be influenced by introgressive hybridization with the dwarf birch, as Kallio et al. (1983) suggested. This assumption is also supported by the fact that height growth was significantly slower in mountain birches originating from our study area than in mountain birches of south Finnish origin when planted in a common garden in south Finland (Kallio and Mäkinen 1978, M. Sulkinoja pers. comm.).

In spring the taller trees had larger buds than the lower trees. The size of buds is known to be dependent on climate of the previous season and nutritional conditions (Kozlowski 1971). But since our trees grow in a restricted and uniform area, we can assume that the variation in bud size is not due to climatic differences but rather a property of the individual trees, and perhaps the microsite. On a given day in spring, large bud size means also that leaf development has started. The tall, early flushing trees produce large leaves, whereas the low trees contain small buds which begin to grow late and produce small leaves. Our results illustrate that trees with the fastest growing leaves at the beginning of the season also have the most advanced leaves in early summer. This development pattern seems to be fairly constant between the years, too, since early bud growth of the spring 1988 correlated with water content in early summer of the previous year. Bud length in 1988 also correlated positively with leaf size in 1987 and 1988. This means that at least the relative differences in leaf size among the trees remain constant even between years of extensive climatic variation, suggesting other than external causes for this relationship.

In autumn, there was considerable individual variation among mountain birches in the beginning of leaf colour change. Trees with the smallest leaves started earliest to change leaf colour. Bud burst and autumnal colour change correlated negatively, indicating that the latest leafing trees tended to shed their leaves the earliest. Accordingly, low, small-leaved, late flushing and early abscising leaves characterised mountain birches with nana-like features, while an opposite set of traits characterised pubescens-like trees.

\section{Plant characteristics and herbivore growth}

Although the quality of birch leaves as food for herbivores changed significantly between the two years, the relative quality of individual trees remained constant as indicated by the significant correlation of the mean herbivore growth rates (Fig. 2).

In 1987, when leaf size was relatively large and the overall food quality for insects high, we found only few marginally significant correlations between leaf traits and herbivore growth. But in 1988, when leaf size was smaller and leaf quality lower, such simple characters as leaf mass and area were good indicators for herbivore growth (Fig. 3). Trees with larger leaves provided relatively high quality food for the herbivores, whereas trees with smaller leaves represented low quality food. Therefore, leaf-chewing insect herbivores on mountain birch should prefer large-leaved trees in seasons of generally low food quality.

The negative correlation between specific leaf weight (fresh or dry) and herbivore growth indicates that the herbivores grow best on trees with the softest leaves. However, the relationship between specific leaf weight and herbivore growth is not that simple, for a decrease in specific leaf weight does not necessarily mean a quality increase for the herbivores. In 1987, specific leaf weight was relatively high but the mean herbivore growth rate was high, too, whereas in 1988 both specific leaf weight and herbivore growth rates were significantly lower (Fig. 4). Within both years specific leaf weight and herbivore growth correlated negatively. This correlation was only marginally significant in the first year, indicating that all trees provided similar nutrition after the warm summer. However, after the cold summer qualitative differences among trees increased, and we found a negative correlation between tree-specific leaf weight and herbivore growth rate.

Leaf water content did not correlate with herbivore growth in any of the sampling dates. This result is con- 
tradictory to our expectation and to other findings (Scriber 1977, Haukioja et al. 1978). An explanation for this result might be that our sample contains a broad range of morphologically and genetically variable trees. As we have seen, trees producing larger leaves leaf out earlier and their leaves grow and mature more rapidly than small-leaved trees. Our results show, however, that despite the higher age of the leaves trees with larger leaves are of superior quality to the herbivores. Therefore, other traits than leaf age, for example genetics of trees determine leaf quality for herbivores. Within a sample of morphologically (and genetically) more similar trees, leaf water content may well be positively correlated with herbivore growth.

\section{Consequences for birch evolution}

The northernmost populations of the mountain birch are phenotypically highly polymorphous. This phenotypic diversity seems to be modified by introgressive hybridisation between $B$. pubescens and $B$. nana (Vaarama and Valanne 1973, Kallio et al. 1983). This means that an extensive array of different genotypes is exposed to selection by a number of biotic and abiotic factors. Selection pressures may vary from year to year. For instance, in favourable years selection may favour largeleaved genotypes since these individuals are the earliest to leaf out in spring, the last to senesce, have the fastest leaf growth, and therefore are the most productive (cf. Harper 1989). On the other hand, these same characteristics may be selected against during cold spells in spring or autumn, a view that is supported by the results of Pelham et al. (1988). They found that leaf size of $B$. pubescens saplings increased significantly with increasing maximum summer temperature and decreased with increasing latitude. In addition, large-leaved (= early leafing) trees provide the herbivores with the highest quality food. If herbivores are important for tree fitness, they might drive the mountain birch towards smaller leaved forms. The potential of herbivores as selection agents becomes obvious at least in outbreak years, when defoliation in combination with unfavourable climatic conditions may cause the death of large numbers of trees (Kallio and Lehtonen 1973, Haukioja et al. 1985, 1988). Climatic variables (Hustich 1952) and herbivore pressure changing dramatically over years (or decades) (Tenow 1972) may thus help to maintain the highly polymorphic mountain birch populations which we find at present.

Acknowledgements - We thank M. Halme, J. Mikola, T. Pakkanen and A. Sydänoja for their help in rearing the larvae, and M. Sulkinoja for information and unpublished data on the Kevo birch garden. L. Iso-Iivari kindly worked up the meteorological data. The staff of the Kevo Subarctic Research Station provided excellent working conditions and facilities. $H$ Müller, S. Neuvonen, J. A. Shykoff and S. C. Stearns gave valuable comments on earlier drafts of the manuscript. The study was financially supported by the Finnish Ministry of
Education and the Swiss Society for the Study of Nature (JS), the Emil Aaltonen Foundation, Turku University Foundation (SH), and the Academy of Finland (EH).

\section{References}

Ayres, M. P. and MacLean, S. F. Jr. 1987. Development of birch leaves and the growth energetics of Epirrita autumnata (Geometridae). - Ecology 68: 558-568.

Crawley, J. M. and Akhteruzzaman, M. 1988. Individual variation in the phenology of oak trees and its consequences for herbivorous insects. - Funct. Ecol. 2: 409-415.

Elkington, T.T. 1968. Introgressive hybridization between $\mathrm{Be}$ tula nana $\mathrm{L}$. and $B$. pubescens Ehrh. in north-west Iceland. - New Phytol. 67: 109-118.

Harper, J. L. 1989. The value of a leaf. - Oecologia 80: 53-58.

Haukioja, E., Niemelä, P., Iso-Iivari, L., Ojala, H. and Aro, E.-M. 1978. Birch leaves as a resource for herbivores. I. Variation in the suitability of leaves. - Rep. Kevo Subarctic Res. Stat. 14: 5-12.

- , Niemelä, P. and Sirén, S. 1985. Foliage phenols and nitrogen in relation to growth, insect damage, and ability to recover after defoliation, in the mountain birch Betula pubescens ssp tortuosa. - Oecologia 65: 214-222.

- , Neuvonen, S., Hanhimäki, S. and Niemelä, P. 1988. The autumnal moth in Fennoscandia. - In: Berryman, A. A. (ed.), Dynamics of forest insect populations. Patterns, causes, implications. Plenum Press, New York, pp. 163178.

Hustich, I. 1952. The recent climatic fluctuation in Finland and its consequences. - Fennia 75: 1-128.

- 1983. Tree-line and tree growth studies during 50 years: some subjective observations. - Nordicana 47: 181-188.

Kallio, P. and Lehtonen, J. 1973. Birch forest damage caused by Oporinia autumnata (Bkh.) in 1965-66 in Utsjoki, N Finland. - Rep. Kevo Subarctic Res. Stat. 10: 55-69.

- and Mäkinen, Y. 1978. Vascular flora of Inari Lapland. 4. Betulaceae. - Rep. Kevo Subarctic Res. Stat. 14: 38-63.

- , Niemi, S. and Sulkinoja, M. 1983. The Fennoscandian birch and its evolution in the marginal forest zone. - Nordicana 47: 101-110.

Karlsson, P. S. and Nordell, K. O. 1987. Growth of Betula pubescens and Pinus silvestris seedlings in a subarctic environment. - Funct. Ecol. 1: 37-44.

- and Nordell, K. O. 1988. Intraspecific variation in nitrogen status and photosynthetic capacity within mountain birch populations. - Holarct. Ecol. 11: 293-297.

Kozlowski, T.T. 1971. Growth and development of trees. Vol. I. - Academic Press, New York.

Leather, S. R. 1986. Host monitoring by aphid migrants: do gymnoparae maximise offspring fitness? - Oecologia 68 367-369.

Pelham, J., Gardiner, A. S., Smith, R. I. and Last, F. T. 1988. Variation in Betula pubescens Ehrh. (Betulaceae) in Scotland: its nature and association with environmental factors. - Bot. J. Linn. Soc. 96: 217-234.

SAS Institute, 1985. SAS User's guide: Statistics, version 5 edition. - SAS Inst., Cary, NC.

Scriber, M. J. 1977. Limiting effects of low leaf-water content on the nitrogen utilization, energy budget, and larval growth of Holophora cecroptia (Lepidoptera: Saturnidae). - Oecologia 28: 269-287.

Sulkinoja, M. 1981. Lapin koivulajien muuntelusta ja risteytymisestä (On the variation and hybridization of Betula species in Lapland. With English summary). - Lapin Tutkimusseuran Vuosik. 22: 22-27.

- and Valanne, T. 1987. Leafing and bud size in Betula provenances of different latitudes and altitudes. - Rep. Kevo Subarctic Res. Stat. 20: 27-33.

Tenow, O. 1972. The outbreak of Oporinia autumnata Bkh. 
and Operophthera spp. (Lep., Geometridae ) in the Scandinavian mountain chain and northern Finland 1862-1968. Zoologiska Bidrag från Uppsala. Suppl. 2: 1-107.

Vaarama, A. and Valanne, T. 1973. On the taxonomy, biology and origin of Betula tortuosa Ledeb. - Rep. Kevo Subarctic Res. Stat. 10: 70-84.
Whitham, T. G. 1983. Host manipulation of parasites: Withinplant variation as a defense against rapidly evolving pests. In: Denno, R. F. and McClure, M. S. (eds), Variable plants and herbivores in natural and managed systems. Academic Press, New York, pp. 15-41. 